\title{
Long-Term Outcome of Percutaneous Coronary Intervention of a Persistent Total Occlusion in the Infarct-Related Coronary Artery
}

Keywords: Open artery hypothesis; Late percutaneous coronary intervention; Myocardial infarction

\section{Editorial}

Primary percutaneous coronary intervention (PCI) is the gold standard treatment in patients with acute myocardial infarction (AMI). Early coronary reperfusion with PCI reduces long-term mortality in patients who present with ST-segment elevation AMI [1-4]. Patients with failed thrombolysis or those with latepresenting AMI may still benefit from PCI by mechanisms independent of myocardial salvage. There are several possible mechanisms of benefit from late PCI outside the time window of myocardial salvage. These may include reduction of ventricular remodeling, decreased ventricular instability with the resulting diminished incidence of ventricular arrhythmias, and provision of collateral vessels to other territories in the event of further coronary artery occlusion [5-10]. In addition to promoting an acute inflammatory response and local edema, reperfusion of IRA with an adequate blood flow at a proper arterial perfusion pressure increases tissue turgor, which may have a scaffolding effect on the vulnerable infarcted territory increasing tissue stiffness to possibly resist infarct expansion [6]. All of these changes in the compromized zone should have a beneficial influence on the remodeling process by altering the properties of the scar tissue and by diminishing the ischemic burden in the non-infarcted myocardium at the border zone [5-7]. All of these plausible mechanisms should be tested in clinical situation to properly evaluate clinical outcomes. However, caution must be exercise when interpreting the results of studies examining this open artery hypothesis. This hypothesis can be tested in its purest sense in experimental animal models, a setting where almost all the variables are known and controlled. However, the clinical situation is much more complex depending on the extension of damaged, ischemic/necrotic territory. Patients may have acute-onchronic coronary artery occlusion in the presence of multivessel disease and well-developed collateral channels. The pattern of necrosis may also be different with areas of necrosis separated by islands of ischemic, stunned, hybernating, or normal cells [11-13]. The random combination of these different variables could have diverse impact on clinical outcomes and events.

The role of late opening of the totally occluded infarct-related coronary artery (IRA) after AMI has been controversial. Although there is a large body of experimental and clinical evidence supporting the concept of late PCI for AMI, the mechanism responsible for the observed benefits remain speculative [1418]. There are observational data suggesting a lower incidence of clinical events, and experimental studies reporting a reduction in adverse left ventricular remodeling after late PCI of a totally

Volume 5 Issue 1 - 2016
Osmar Antonio Centurión ${ }^{1,2 *}$
${ }^{1}$ Department of Health Sciences's Investigation, Sanatorio
Metropolitano, Fernando de la Mora, Paraguay
${ }^{2}$ Cardiology Division, First Department of Internal Medicine,
Asunción National University, Paraguay
*Corresponding author: Osmar Antonio Centurión,
Professor of Medicine, Asuncion National University,
Department of Health Sciences's Investigation, Sanatorio
Metropolitano, Cardiology Division, First Department of
Internal Medicine, Asunción National University, Teniente
Ettiene 215 c/ Ruta Mariscal Estigarribia, Fernando de la
Mora, Asunción, Paraguay, Email:
osmarcenturion@ @hotmail.com
Received: January 05, 2016 | Published: January 12, 2016

occluded IRA. In order to properly test the open artery hypothesis, vessel patency should be assessed days to weeks after AMI and a demonstrable beneficial effect should be independent of early left ventricular (LV) function. This approach will diminish the influence of spontaneous closure of the vessels that were open early post AMI or the spontaneous opening of the vessels that were closed early. White $\mathrm{H}$ et al. [19], examined infarct vessel patency and LV function in their patients one month after the first AMI. These two parameters, vessel patency and LV function, were found independently predictive of survival over 3 years of followup on multivariate analysis. They observed that the beneficial effect of a patent vessel was greatest when the IRA supplied more than $25 \%$ of the myocardium and the ejection fraction was less than $50 \%$. However, it is very important to state that serial assessment of left ventricular function was not performed. Therefore, the mechanism for the benefit is unclear. In a similar study [20] done in a cohort of 58 patients, infarct-related vessel patency was assessed 7 to 10 days after AMI. In the first week of AMI, left ventricular function was similar in patients with a patent or an occluded vessel. However, over the subsequent year those with an occluded IRA developed the most ventricular dilatation and the greatest decrease in ejection fraction. They observed an intermediate effect when the IRA was patent but possessed a minimal luminal diameter of less than $1.5 \mathrm{~mm}$. Hence, it seems that there is a dose response inverse relationship between the degree of stenosis and the quantity of remodeling, suggesting an important beneficial effect of late PCI in opening occluded vessels or severe stenotic arteries. The independent effect of a patent IRA on survival and the importance of the quality of perfusion are 
further reinforced by other reported studies [21-25]. These latter investigations demontrated that late patency of an IRA seems to have a positive influence on remodeling and survival and that this effect is independent of any acute reduction of infarct size secondary to reperfusion during the acute phase of an evolving AMI.

Nevertheless, despite these favorable observational and experimental clinical findings, the Occluded Artery Trial (OAT) failed to confirm these observations in a large prospective randomized clinical study [26].

The OAT investigation demonstrated that PCI did not reduce the occurrence of death, reinfarction, or heart failure, and that there was a trend toward excess reinfarction during 4 years of follow-up in stable patients with occlusion of the IRA 3 to 28 days after AMI. There was no interaction between treatment effect and any subgroup variable, namely, age, sex, race or ethnic group, infarct-related artery, ejection fraction, diabetes, Killip class, and the time from myocardial infarction to randomization [26]. Surprisingly, the OAT did not confirm the hypothesis that late PCI after AMI in stable patients with a totally occluded IRA would reduce the occurrence of death, reinfarction, or hospitalization compared with optimal medical therapy alone. However, there are interesting aspects in the design of the trial, the type of stents utilized, and the duration of medical treatment that need to be mentioned. The large majority of stents placed during protocol PCI were bare metal stents, only $8 \%$ of PCI patients received dug eluting stents. Considering the medical management in this trial, in most OAT patients clopidogrel was stopped by the 4-month visit. Prolonged treatment with thienopyridines was not required. Therefore, it was used only in $15 \%$ of the patients. In addition, a relatively large number of patients were not studied due to rigid exclusion criteria, a fact that might have precluded clinical benefit of late PCI in certain subgroup of patients. Indeed, there was an early significant benefit of assignment to PCI on the prevalence of angina. Dyspnea and angina were less common in the PCI arm through 24 months. These results suggest that revascularization should be used selectively for the management of angina in patients with persistent total occlusion of the IRA. Despite the conclusive clinical findings of the OAT there still remain additional experimental mechanisms of benefit in late reperfusion therapy. However, there is a robust long-term followup data which confirms that there is no benefit on cardiovascular events and clinical outcomes associated with a routine strategy of late PCI in stable AMI patients with persistent total occlusion of the IRA. The selective utilization of PCI in the revascularization of ischemic myocardium for the management of angina in patients with persistent total occlusion of the IRA definitely provides clinical benefit in this subgroup of patients.

\section{References}

1. O'Gara P, Kushner FG, Ascheim DD, Donald EC, Mina k, et al. (2013) 2013 ACCF/AHA guideline for the management of ST-elevation myocardial infarction: executive summary: a report of the American College of Cardiology Foundation/American Heart Association Task Force on Practice Guidelines. J Am Coll Cardiol 127: 529-555.

2. Bhatt DL (2013) Timely PCI for STEMI: still the treatment of choice. N Engl J Med 368(15): 1446-1447.
3. Park DW, Clare RM, Schulte PJ, Pieper KS, Shaw LK, et al. (2014) Extent, location, and clinical significance of non-infarct-related coronary artery disease among patients with ST-elevation myocardial infarction. JAMA 312(19): 2019-2027.

4. Garcia S, Sandoval Y, Roukoz H, Adabag S, Canoniero M, et al. (2013) Outcomes after complete versus incomplete revascularization of patients with multivessel coronary artery disease: a meta-analysis of 89,883 patients enrolled in randomized clinical trials and observational studies. J Am Coll Cardiol 62(16): 1421-1431.

5. Roberts CS, Schoen FJ, Kloner RA (1983) Effects of coronary reperfusion on myocardial hemorrhage and infarct healing. Am Cardiol 52: 610-614.

6. Pirzada FA, Weiner JM, Hood WB (1978) Experimental myocardial infarction. Accelerated myocardial stiffening related to coronary reperfusion following ischemia. Chest 74(2): 190-195.

7. Braunwald E (1989) Myocardial reperfusion, limitation of infarct size, reduction of left ventricular dysfunction, and improved survival. Should the paradigm be expanded? Circulation 79(2): 441444.

8. Vannan MA, Taylor DJE (1992) Ventricular remodeling after myocardial infarction. Br Heart J 68: 257-259.

9. Kersschot IE, Brugada P, Ramentol M, Zehender M, Waldecker $B$, et al. (1986) Effects of early reperfusion in acute myocardial infarction on arrhythmias induced by programmed stimulation: A prospective randomized study. J Am Coll Cardiol 7(6): 1234-1242.

10. Hohnloser SH, Franck P, Klingenheben T, Zabel M, Just H (1994) Open infarct artery, late potentials, and other prognostic factors in patients after acute myocardial infarction in the thrombolytic era. A prospective trial. Circulation 90(4): 1747-1756.

11. Klonner RA (1989) No-reflow revisited. J Am Coll Cardiol 14(7): 1814-1815.

12. Nidorf SM, Siu SC, Galambos G, Arthur EW, Michael HP, et al (1993) Benefit of late coronary reperfusion on ventricular morphology and function after myocardial infarction. Journal of the American College of Cardiology 21(3): 683-691.

13. McMurray J, Rankin A (1994) Treatment of myocardial infarction, unstable ungina, and ungina pectoris. Br Med J 309(6965): 13431350.

14. Sabia PJ, Powers ER, Ragosta R, Sarembock IJ, Burwell LR, et al (1992) An association between collateral blood flow and myocardial viability in patients with recent myocardial infarction. N Engl J Med 327(26): 1825-1831.

15. Brugada D, DeSwart H, Smeets JLRM, Wellens HJJ (1988) The role of collateral blood supply in ventricular tachycardia after myocardial infarction. Eur Heart J 9(10): 1104-1111.

16. Janse MJ, Witt AL (1989) Electrophysiological mechanisms of ventricular arrhythmias resulting from myocardial ischemia and infarction. Physiol Rev 69(4): 1049-1069.

17. Bonaduce D, Marciano F, Petretta M, Migaux ML, Morgano G, et al. (1994) Effect of converting enzime inhibition on heart period variability in patients with acute myocardial infarction. Circulation 90(1): 108-113.

18. Sogaard P, Gotzsche CO, Ravilde J, Aage N, Kristian T, et al. (1994) Ventricular arrhythmias in the acute and chronic phases after myocardial infarction. Effect of intervention with captopril. Circulation 90(1): 101-107. 
19. White HD, Cross DB, Elliot JM, Norris RM, Yee TW (1994) Long-term prognostic importance of patency of the infarct-related coronary artery after thrombolytic therapy for acute myocardial infarction. Circulation 89(1): 61-67.

20. Leung WH, Lau CP (1992) Effects of severity of residual stenosis of the infarct-related coronary artery on left ventricular dilatation and function after acute myocardial infarction. J Am Coll Cardiol 20(2): 307-313.

21. Gaudron P, Eilles C, Kugler I, Ertl G (1993) Progressive left ventricular dysfunction and remodeling after acute myocardial infarction. Potential mechanisms and early predictors. Circulation 87(3): 755-763.

22. Popovic AD, Neskovic AN, Babic R, Obradović V, Bozinović L, et al. (1994) Independent impact of thrombolytic therapy and vessel patency on left ventricular dilatation after myocardial infarction. Serial echocardiographic follow-up. Circulation 90(2): 800-807.
23. Galvani M, Ottani F, Ferrini D, Francesco S, Franco R, et al. (1993) Patency of the infarct-related artery and left ventricular function as the major determinants of survival after Q-wave acute myocardial infarction. Am J Cardiol 71(1): 1-7.

24. Meijer A, Verheugt FWA, van Eenige MJ, Werter CJ (1994) Left ventricular function at 3 months after successful thrombolysis. Impact of reocclusion without reinfarction on ejection fraction, regional function, and remodeling. Circulation 90(4): 1706-1714.

25. Centurión OA (2007) The open artery hypothesis: Beneficial effects and long-term prognostic importance of patency of the infarctrelated coronary artery. Angiology 58(1): 34-44.

26. Hochman JS, Lamas GA, Buller CE, Dzavik V, Reynolds HR, et al. (2006) Coronary intervention for persistent occlusion after myocardial infarction. N Engl J Med 355(23): 2395-2407. 